POLITEKNIK NEGERI NUSA UTARA

\title{
PERILAKU HIDUP BERSIH SEHAT TATANAN RUMAH TANGGA DI DAERAH KEPULAUAN
}

\section{CLEAN AND HEALTHY LIVING BEHAVIOR HOUSEHOLD ORDER IN ISLAND AREA}

\author{
Mareike Doherty Patras, Yeanneke Liesbeth Tinungki \\ Jurusan Kesehatan Program Studi Keperawatan Politeknik Negeri Nusa Utara \\ Korenspondesi mareikepatrasmp@gmail,.com
}

\begin{abstract}
Abstrak: Perilaku Hidup Bersih dan Sehat (PHBS) merupakan cerminan pola hidup keluarga yang senantiasa memperhatikan dan menjaga kesehatan seluruh anggota keluarga. Semua perilaku kesehatan yang dilakukan atas kesadaran sehingga keluarga atau anggota keluarga dapat menolong dirinya sendiri dibidang kesehatan dan dapat berperan aktif dalam kegiatan-kegiatan dibidang kesehatan di masyarakat. Hal ini terjadi karena kurangnya perilaku hidup bersih sehat keluarga. Guna mencegah penyakit menular dan tidak menular, setiap anggota rumah tangga perlu diberdayakan,dalam melaksanakan 10 (sepuluh) indikator PHBS Pelaksanaan PHBS Kabupaten Sangihe tahun 2017 50,40\%. Di Kecamatan Tabukan Selatan Tengah $280 \mathrm{KK}$ Keluarga yang di pantau ,yang ber PHBS 114 (40,2\%). Tujuan penelitian ingin mengetahui Hubungan Pengetahuan dan Sikap Keluarga dengan Perilaku Hidup Bersih Sehat. Metode penelitian dengan menggunakan rancangan Cross sectional study. Hasil penelitian tidak ada hubungan pengetahuan dengan penerapan Perilaku hidup Bersih Sehat diperoleh nilai $\mathrm{P}$ yaitu $=0,171>\alpha \quad 0,05$ dan ada hubungan antara sikap dengan penerapan Perilaku hidup Bersih Sehat nilai p value $0,03<\underset{\alpha}{\alpha}(0.05)$. Disarankan agar setiap anggota keluarga termotivasi melaksanakan 10 indikator PHBS
\end{abstract}

Kata Kunci: Pengetahuan, Sikap, Indikator PHBS.

Abstract: Clean and Healty living behavior showed of fammily pattern live style in order to prevent infectious and non-communicable diseases, every member of the household needs to be empowered in implementing 10 (ten) indicators of Clean and Healthy Living Behavior. In 2017 the implementation in Sangihe District was 50.40\%. The family monitored in Tabukan Selatan Tengah Subdistrict were 280 families, apply clean and healthy living behavior about 114 (40.2\%). Method of those reaseach apply cross sectional study, design and the result of the research show that was not a relationship between knowledge and clean healthy life behavior with $p$ value $0.016<\alpha(0.05)$ and those was a relationship between attitude and clean healthy lifestyle, $p$ value $0.03<\alpha(0.05)$. The member of fammily incentive to motivate ten (10) standards of Clean Healty living behavior.

Keyword: Knowledge, Atitude, Indicators of PHBS.

\section{PENDAHULUAN}

Perilaku Hidup Bersih dan Sehat (PHBS) merupakan cerminan pola hidup keluarga yang senantiasa memperhatikan dan menjaga kesehatan seluruh anggota keluarga. Semua perilaku kesehatan yang dilakukan atas kesadaran sehingga keluarga atau anggota keluarga dapat menolong dirinya sendiri dibidang kesehatan dan dapat berperan aktif dalam kegiatan-kegiatan dibidang kesehatan di masyarakat. Mencegah lebih baik dari pada mengobati, prinsip kesehatan inilah yang menjadi dasar dari penerapan PHBS. Kegiatan PHBS tidak dapat terlaksana apabila tidak ada kesadaran dari seluruh anggota keluarga itu sendiri dan PHBS ini harus diterapkan sedini mungkin di tiap keluarga agar menjadi kebiasaan positif dalam memelihara kesehatan (Proverawati \& Rahmawati, 2012).

Beberapa anggota rumah tangga mempunyai masa rawan terkena penyakit menular dan penyakit tidak menular. Data penyakit menular diare berjumlah 9.517 kasus, TB paru 136 kasus, Demam Berdarah (DBD) 55 kasus dan malaria 133 kasus (Dinas Kesehatan Sangihe, 2017). 
Untuk mencegah penyakit menular dan penyakit tidak menular setiap anggota rumah tangga perlu diberdayakan guna melaksanakan atau menerapkan 10 (sepuluh) indikator Perilaku Hidup Bersih Sehat rumah tangga (Kemenkes RI, 2011; Kemenkes RI, 2012). Hasil Penelitian yang dilakukan oleh Nur'Ain Napu, (2012) tentang gambaran perilaku keluarga tentang PHBS di Desa Tunggulo Selatan Kecamatan Tilongkabila Kabupaten Bone bolango, berpengetahuan kurang $88 \%$. dan bersikap baik $56 \%$.

Profil Kesehatan Provinsi Sulawesi Utara Tahun 2016, Pelaksanaan PHBS di Propinsi SULUT $66,2 \%$, Kabupaten Sangihe 40,2\%. Menurut data survei rumah tangga di tiap Kecamatan Kabupaten Sangihe tahun 2017 Pelaksanaan PHBS sejumlah 50,40\%., Kecamatan Tabukan Selatan Tengah dengan jumlah Kepala Keluarga 814, Keluarga yang dipantau 280 dan yang ber PHBS sejumlah. 114 (40,71\%) KK. Penderita penyakit diare 122 orang, TB paru 7 orang dan Hipertensi 287 (75,85\%) orang (Dinkes Sulut, 2016).

Hasil kajian dalam rumah tangga tangga menerapkan 10 indikator PHBS di Kabupaten Kepulauan Sangihe berupa persalinan ditolong oleh tenaga kesehatan $90 \%$, ASI ekslusif $42 \%$, penimbangan balita 95\%, menggunakan air bersih $89 \%$, mencuci tangan dengan sabun $80 \%$, menggunakan jamban sehat $79 \%$, memberantas jentik nyamuk dirumah 40\%, konsumsi sayur dan buah tiap hari 50\%, melakukan aktivitas fisik setiap hari $30 \%$, dan tidak merokok dalam rumah 35\% (Dinkes Sangihe, 2012). Tujuan penelitian ini yaitu untuk melihat hubungan antara pengetahuan dan sikap keluarga dengan penerapan PHBS di Wilayah Kerja Puskesmas Salurang Kecamatan Tabukan Selatan Tengah Kabupaten Kepulauan Sangihe.

\section{METODE PENELITIAN}

Jenis penelitian survey analitik menggunakan rancangan Cross sectional study yang bertujuan mengembangkan dan menjelaskan hubungan antar Variabel bebas dan variabel terikat berupa pengetahuan dan sikap keluarga tentang 10 indikator PHBS dengan variabel terikat penerapan perilaku hidup bersih sehat di Kampung Salurang Kecamatan Tabukan Selatan Tengah. Waktu penelitian mulai bulan Juni 2020 sampai dengan November 2020 bertempat di Kampung Salurang Kecamatan Tabukan Selatan Tengah. Pengambilan besar sampel menggunakan rumus Stenly Lameshow dengan populasi tidak diketahui (Notoadmodjo, 2012). Jumlah sampel 96 orang, teknik pengambilan sampel berupa simple random sampling atau pengambilan sampel secara sederhana. Skala pengukuran variabel pengetahuan, sikap dan tindakan nilai skor $77 \%-100 \%$ baik diberi angka 1 (satu), skor 76-100\% cukup diberi angka 2 (dua) dan skor 56-75\% kurang baik diberi angka 3. Pengolahan data menggunakan uji Chi-Square dengan SPSS 21

\section{HASIL DAN PEMBAHASAN}

Kampung Salurang adalah salah satu Desa yang berada di dalam wilayah kecamatan Tabukan Selatan Tengah dengan jarak tempuh dari Kecamatan Tahuna \pm 2 jam perjalanan dengan menggunakan kendaraan beroda 2 (dua) terbagi atas 5 dusun (lindongan) berpenduduk 696 jiwa, jumlah rumah 253. Sebagian besar bekerja sebagai Petani dan Nelayan dan mayoritas beragama Kristen $99,9 \%$ dan 1 orang $(0,1 \%)$ beragama islam.

1. Analisa Univariat

Tabel 1. Distribusi responden berdasarkan pengetahuan,

\begin{tabular}{lcc}
\hline KATEGORI & $\begin{array}{c}\text { JUMLAH } \\
\text { (n) }\end{array}$ & $\begin{array}{c}\text { PERSENTASE } \\
\text { (\%) }\end{array}$ \\
\hline Pengetahuan PHBS & & \\
Baik & 34 & 35,4 \\
Cukup & 59 & 61,5 \\
Kurang & 3 & 3,1 \\
Jumlah & 96 & 100,0 \\
Sikap PHBS & & \\
Baik & 93 & 96,9 \\
Cukup & 0 & 0 \\
Kurang & 3 & 3,1 \\
$\quad$ Jumlah & 96 & 100,0 \\
Penerapan PHBS & & \\
Baik & 23 & 24,0 \\
Cukup & 57 & 59,4 \\
Kurang & 16 & 16,7 \\
Jumlah & 96 & 100,0 \\
\hline
\end{tabular}

Dari data tabel 1 didapat responden sebagian besar berpengetahuan cukup baik 59 orang $(65,5 \%)$, hanya 
$1,22 \%$ bersikap kurang baik. karena sebagian besar responden belum mengetahui tentang beberapa indikator PHBS rumah tangga, belum memahami pentingnya ASI eksklusif bagi bayi, kegunaan dari mencuci tangan dengan air bersih yang mengalir, tujuan aktivitas fisik setiap hari, tujuan 3M Plus, dampak merokok didalam rumah. Hal ini berbeda dengan penelitian yang dilakukan oleh Saini (2019) tentang Pengetahuan Dan Sikap Keluarga Dalam Pelaksanaan Perilaku Hidup Bersih Dan Sehat Di Wilayah Kerja Puskesmas Sombaopu Gowa, responden memiliki pengetahuan baik 17 responden (70,8\%). Pengetahuan (Knowledge) adalah hasil dari suatu proses pembelajaran seseorang terhadap sesuatu baik itu yang didengar maupun yang dilihat (Fitriani, 2011). Pengetahuan adalah hasil dari tahu dan ini terjadi setelah orang melakukan pengindraan terhadap suatu objek tertentu. Pengetahuan atau kognitif adalah domain yang sangat penting dalam membentuk tindakan (Notoadmodjo, 2010).

Sikap responden dalam menerapkan atau melaksanakan PHBS di Kampung Salurang berada pada kategori baik $93(96,9)$, hanya 1 (satu) orang responden yang bersikap kurang baik terhadap PHBS. Hampir $100 \%$ responden merespon dengan benar setiap pernyataan sikap akan menerapkan atau melaksanakan 10 indikator PHBS melalui kuisioner. Penelitian yang dilakukan oleh Meilisa (2013) didapatkan bahwa kepala keluarga yang berada di Kelurahan Miranti Pandak bersikap positif dan negatif $50 \%$. Sikap adalah respon tertutup seorang terhadap stimulus atau objek tertentu yang sudah melibatkan fakta pendapat dan emosi yang bersangkutan. Sikap juga merupakan kesiapan atau kesediaan untuk bertindak dan bukan merupakan pelaksanaaan motif tertentu, dalam kata lain fungsi sikap belum merupakan tindakan atau aktivitas tetapi merupakan predesposisi perilaku (Notoadmodjo, 2010).

Hasil penelitian, sebagian besar responden cukup baik dalam rnenerapkan Perilaku Hidup Bersih Sehat di Kampung Salurang Kecamatan Tabukan Selatan Tengah. Ini karena masih ada beberapa indikantor yang kurang diterapkan seperti kurangnya mengkonsumsi buah dan sayur setiap hari, masih banyak keluarga yang kurang menerapkan $3 \mathrm{M}$ plus membuang sampah di sembarang tempat seperti membuang dan membakar sampah di rawa yang berada di belakang rumah dan ada sebagian besar anggota rumah tangga yang merokok di dalam rumah.

Berdasarkan hasil penelitian dari Anggriani (2018) tentang Penerapan nilai-nilai PHBS dalam Rumah Tangga di Kelurahan Sungai Bangkong Kota Pontianak, dari ketiga informan tersebut dapat dikategorikan baik namun penerapannya masih belum maksimal karena belum melaksasakan penerapan mengkonsumsi buahbuahan setiap hari. Penerapan PHBS adalah sekumpulan perilaku yang diperkirakan atas dasar kesadaran sebagai hasil pembelajaran yang menjadikan seseorang atau keluarga dapat menolong diri sendiri di bidang kesehatan dan berperan aktif dalam mewujudkan kesehatan masyarakatnya (Kemenkes RI, 2017).

2. Analisis bivariat

Tabel 2. Distribusi responden hubungan pengetahuan dengan penerapan PHBS

\begin{tabular}{|c|c|c|c|c|c|c|c|}
\hline \multirow[b]{3}{*}{ Pen- } & \multirow[b]{3}{*}{ Baik } & \multicolumn{3}{|c|}{ Penerapan } & \multirow{3}{*}{$\begin{array}{l}\text { Total } \\
-\quad 34\end{array}$} & \multirow{3}{*}{$\begin{array}{c}\% \\
35,4\end{array}$} & \multirow[t]{3}{*}{ P-value } \\
\hline & & Baik & Cukup & Kurang & & & \\
\hline & & 10 & 19 & 5 & & & \\
\hline geta- & Cukup & 13 & 37 & 9 & 59 & 61,5 & 0,171 \\
\hline huan & Kurang & 0 & 1 & 2 & 3 & 3,1 & \\
\hline Total & & 23 & 57 & 16 & 96 & 100 & \\
\hline
\end{tabular}

Dari Tabel hasil analissis bi-variat hubungan antara pengetahuan dengan penerapan PHBS, paling banyak memiliki pengetahuan PHBS Cukup dan penerapan PHBS yang cukup baik sejumlah 37 responden dengan nilai $\mathrm{P}$ - value $0,171>\alpha 0,05$ ini berarti tidak ada hubungan yang bermakna antara pengetahuan dengan perilaku hidup bersih sehat di Kampung Salurang Kecamatan Tabukan Selatan Tengah Kabupaten Sangihe. Pengetahuan adalah hasil dari suatu proses pembelajaran seseorang terhadap sesuatu baik itu yang didengar maupun yang dilihat (Fitriani, 2011)

Hasil Penelitian ini sama dengan yang dilakukan oleh Meilisa (2013), Hubungan Pengetahuan dan Sikap Keluarga Tentang PHBS dengan Penerapan PHBS 
pada Tatanan Rumah Tangga di Kelurahan Miranti Pandak, dari hasil penelitian didapatkan bahwa $p$-value $0.251>\alpha(0.05)$ tidak ada hubungan antara pengetahuan dan penerapan PHBS di Kelurahan Miranti Pandak. Berbeda dengan hasil penelitian yang dilakukan oleh Yuliana N. S (2019), ada hubungan antara pengetahuan dengan penerapan PHBS dimana $p$ value $0,001<\alpha$ (0.05),

Tabel 3. Distribusi responden berdasarkan hubungan sikap dan penerapan $P H B S$

\begin{tabular}{|c|c|c|c|c|c|c|c|}
\hline & & \multicolumn{3}{|c|}{ Penerapan } & \multirow[t]{2}{*}{ Total } & \multirow[t]{2}{*}{$\%$} & \multirow[b]{2}{*}{$\begin{array}{c}\text { P- } \\
\text { value }\end{array}$} \\
\hline & & Baik & $\begin{array}{c}\text { Cuk } \\
\text { up }\end{array}$ & $\begin{array}{c}\text { Kura } \\
\text { ng }\end{array}$ & & & \\
\hline & Baik & 22 & 57 & 14 & 93 & 96,9 & \\
\hline \multirow[t]{2}{*}{ Sikap } & Cukup & 0 & 0 & 0 & 0 & 0 & \\
\hline & Kurang & 1 & 0 & 2 & 3 & 3,1 & 0,037 \\
\hline Total & & 23 & 23 & 57 & 16 & 96 & \\
\hline
\end{tabular}

Hasil analisis bivariat hubungan antara Sikap dengan penerapn PHBS pada umumnya memiliki sikap baik dan penerapan yang cukup baik sejumlah 57 responden. Hasil uji Chi Square diperoleh P-value 0,037 < $\alpha 0,05$ hal ini berarti bahwa ada hubungan yang bermakna antara sikap responden dengan penerapan PHBS di Kampung Salurang Kecamatan Tabukan Selatan Tengah. Responden memiliki pengetahuan baik namun tidak tidak menerapkan PHBS dengan baik karena masih ada 14 responden yang kurang menerapkan PHBS di Keluarga karena kurangnya kesadaran keluarga dalam menerapkan PHBS dengan baik bukan hanya bersikap tapi menerapkan atau melakukan 10 indikator PHBS dengan baik, Menurut Notoatmodjo (2012), Perilaku hidup sehat (healthy life style) Merupakan perilaku yang berhubungan dengan usahausaha untuk meningkatkan kesehatan dengan gaya hidup sehat yang meliputi makan menu seimbang, olah raga yang teratur, tidak merokok, istirahat cukup, menjaga perilaku yang positif bagi kesehatan. Perilaku Hidup Bersih dan Sehat (PHBS) adalah cerminan pola hidup keluarga yang senantiasa memperhatikan dan menjaga kesehatan seluruh anggota keluarga. Semua perilaku kesehatan yang dilakukan atas kesadaran sehingga anggota keluarga atau sekeluarga dapat menolong dirinya sendiri di bidang kesehatan dan dapat berperan aktif dalam kegiatan-kegiatan kesehatan di masyarakat (Proverati dan Rahmawati, 2012).

\section{KESIMPULAN DAN SARAN}

Dari hasil penelitian dapat disimpulkan bahwa tidak ada hubungan antara pengetahuan dengan Penerapan Perilaku Hidup Bersih Sehat pada masyarakat pesisir di Kampung Salurang Kecamatan Tabukan Selatan Tengah dan ada hubungan antara sikap keluarga dengan Penerapan Perilaku Hidup Bersih sehat pada Masyarakat Pesisir di Kampung Salurang Kecamatan Tabukan Selatan Tengah.

Disarankan agar seluruh keluarga yang ada di Kampung Salurang Kecamatan Tabukan Selatan Tengah termotivasi menerapkan 10 indikator PHBS dengan baik. Pemerintah dan petugas kesehatan yang ada di Wilayah Kerja Puskesmas Manalu kiranya selalu memotivasi keluarga yang berada di kampung Salurang dengan memberikan penyuluhan 10 indikator PHBS Rumah Tangga.

\section{DAFTAR PUSTAKA}

Angriani G. D (2018), Penerapan nilai-nilai PHBS dalam Rumah Tangga di Kelurahan Sungai Bangkong Kota Pontianak. Artikel (online) diakses 13 Januari 2021

Dinas Kesehatan Sulut. 2016. Profil Dinas Kesehatan Sulut Manado. Dinkes Sulut, (Online), https://dinkes.sulutprov.go.id/, diakses 01 April 2020.

Dinas Kesehatan Sangihe. 2012. Profil Kesehatan Kabupaten Sangihe. (Online), https://psp.nawasis/info/kepsangihe/, diakses 04 September 2020.

Dinas Kesehatan Sangihe. 2017. Profil Dinas Kesehatan Sangihe. Dinkes Sangihe, (Online), https://docplayer.info/129890408-Profilkesehatan-kabupaten-kepulauan-sangihe.html, diakses 04 September 2020.

Fitriani. 2011. Promosi Kesehatan. Yogyakarta; Graha Ilmu. 
Kemenkes RI. 2011. Pedoman Pembinaan Perilaku Hidup Bersih Sehat. (Online) https://promkes.kemkes.go.id/pedoman-phbs, diakses pada tanggal 01 April 2020.

Kemenkes RI. 2012. Rumah tangga dengan Perilaku Hidup Bersih dan Sehat. (Online), https://www.kemkes.go.id diakses 15 April2020

Kemenkes RI (2017 ), Profil Kesehatan Indonesia, https://www.kemkes.go.id diakses 1 April 2020 Meilisa, S. 2013. Hubungan Pengetahuan Dan Sikap Keluarga Tentang PHBS Dengan Penerapan PHBS Di Tatanan Rumah Tangga. Unri (Online) https://repository.unri.ac.id/, diakses 10 April 2020.

Napu, N. 2012. Peran Keluarga Dalam Melaksanakan Perilaku Hidup Bersih Sehat. (Online), https://r.search.yahoo.com/ diakses 11 Desember 2020.

Notoadmodjo, S. 2010. Promosi Kesehatan Teori dan Aplikasi. Jakarta; Rineka Cipta.
Notoadmodjo, S. 2010. Metodologi. Jakarta; Rineka Cipta.

Notoadmodjo, S. 2012. Promosi Kesehatan dan Perilaku Kesehatan Jakarta. Edisi Revisi. Jakarta; Rineka Cipta.

Proverawati., Rahmawati. 2012. Perilaku Hidup Bersih dan Sehat. Jakarta; Nuha medika.

Saini, S. 2019. Pengetahuan Dan Sikap Keluarga Dalam Pelaksanaan Perilaku Hidup Bersih Dan Sehat Di Wilayah Kerja Puskesmas Sombaopu Gowa, (Online), https://media.neliti.com/media/publications, diakses 12 Nopember 2020.

Yuliana N. S, Adisti A. K., Ardiansa, A. T. T. 2019. Hubungan Antara Pengetahuan dan Sikap dengan Perilaku Kesehatan di Kelurahan Kima Atas Kota Manado, (Online), https://ejournal.unsrat.ac.id/index.php/kesmas/a rticle/download/, diakses tanggal 16 Desember 2020. 